\title{
Learning in multiple contexts: are there intra-, cross- and transcontextual effects on the learner's motivation and help seeking?
}

\author{
Jean-Luc Gurtner • Alida Gulfi • Philippe A. Genoud • \\ Bernardo de Rocha Trindade • Jérôme Schumacher
}

Received: 15 September 2010 / Revised: 28 June 2011 / Accepted: 15 July 2011 /

Published online: 2 November 2011

(C) Instituto Superior de Psicologia Aplicada, Lisboa, Portugal and Springer Science+Business Media BV 2011

\begin{abstract}
In Germany, Austria and Switzerland, the majority of 15-19-year olds follow vocational education programmes within a dual-track system, spending most of their time in a company and going to school only 1 day each week. With their separate aims, content and sociological organisation, the company and the school can be considered as two distinct contexts within which apprentices have to acquire the various skills and competencies of their future occupation. In this paper, the development of apprentices' learning intentions and motivation to learn, subjective competence, perceived utility of what is learned and estimated learning place attractiveness (study 1) as well as their readiness to seek help in these different contexts over the year of training (study 2) is analysed using both longitudinal and cross-sectional data. The findings show significant differences in apprentices' motivation, their beliefs and their readiness to seek help in the different contexts throughout the training. Moderate (cross-different contexts, same time) as well as transcontextual (different contexts, different times) influences can also be seen. These results emphasise the importance of a careful delimitation of contexts when studying the
\end{abstract}

J.-L. Gurtner $(\triangle) \cdot$ A. Gulfi $\cdot$ P. A. Genoud $\cdot$ B. de Rocha Trindade

Department of Education, University of Fribourg $(\mathrm{CH})$, rue Faucigny 2, 1700 Fribourg, Switzerland

e-mail: jean-luc.gurtner@unifr.ch

B. de Rocha Trindade

e-mail: Bernardo.derocha@unifr.ch

P. A. Genoud

Department of Psychology, University of Fribourg $(\mathrm{CH})$, rue Faucigny 2, 1700 Fribourg, Switzerland e-mail: philippe.genoud@unifr.ch

\section{A. Gulfi}

University of Applied Sciences of Western Switzerland, rue Jean-Prouvé 10, 1762 Givisiez, Switzerland e-mail: Alida.Gulfi@hef-ts.ch

J. Schumacher

University of Teacher Education, 36 rue de Morat, 1700 Fribourg, Switzerland

e-mail: Schumacherje@edufr.ch 
impact of contextual factors on learners' motivation and behaviours; they also suggest that motivation within one of these contexts can indirectly affect the learner's motivation within another of these contexts. It is therefore likely that, by using these various dynamics appropriately, educators might temporarily sustain learners' motivation in an unappreciated context by having recourse to a better accepted one.

Keywords Vocational training - Workplace vs. classroom learning · Attitudes towards help · Motivation in context

\section{Introduction}

The dual-track model for vocational training as multi-contextual

After finishing their ninth year of compulsory school, around the age of 15 or 16 , approximately three quarters of all Swiss youngsters, boys as well as girls, attend a vocational education programme for 3 to 4 years depending on the profession chosen. Although some full-time school programmes exist, in particular for commerce, nursing and for some specialisations in the hand-craft sector, the Swiss Vocational Education and Training system is mainly based on the dual-track model: for the whole period of their training, apprentices attend school for only 1 or 1.5 days a week while for the rest of the week they work in a company with whom they have signed an apprenticeship contract. This model is also very common in Germany and Austria.

Despite a slight decline in recent years in favour of general education programmes, these combined school/work programmes remain very popular in Switzerland, and the numbers of student enrolments in these programmes continue to be higher than in any EU country (58.3\% in 2005, according to Bonoli and Ghisla 2008).

In the work segment, the apprentice has the opportunity to engage in genuine activities in the chosen field under the professional guidance of a supervisor, thus gradually developing her/his professional identity. Generally, within the companies, apprentices are soon allocated simple tasks to accomplish autonomously. The rest of the time, they serve as helpers, assisting older professionals in carrying out more complex activities.

At school, they attend general education courses, usually in languages, mathematics or history, as well as courses, which are more specific to the professional sector in which they are involved, such as electricity, mechanics or office skills. For the general education courses, the teachers hold a university degree in the subject, but the teachers of the more specific courses come from the professional sector and have generally worked in companies for many years before becoming teachers. Unlike the general education teachers, they have much in common with the apprentices, having been apprentices themselves and having had professional experiences of the same nature as those of the apprentices.

Although the school and the companies are supposed to work hand in hand, they do not have a great deal in common as regards their aims, content or sociological organisation, as Table 1 reveals. In view of this, the dual-track system can be viewed as requiring the learning of one profession from multiple contexts. The bundling together of knowledge, skills and attitudes acquired in these various contexts is incumbent on the apprentice her/himself. 
Table 1 Contrasting characteristics of the school and the workplace contexts

\begin{tabular}{|c|c|c|c|}
\hline \multirow[t]{2}{*}{ Characteristics } & \multicolumn{2}{|l|}{ School } & \multirow[t]{2}{*}{ Workplace } \\
\hline & $\begin{array}{l}\text { General } \\
\text { education }\end{array}$ & Specific courses & \\
\hline Actors involved & $\begin{array}{l}\text { Students and } \\
\text { teachers only }\end{array}$ & Apprentices and experts & $\begin{array}{l}\text { Persons with very varied } \\
\text { status }\end{array}$ \\
\hline Type of mentor & Teacher & Teacher & Supervisor \\
\hline $\begin{array}{l}\text { Apprentice sense of } \\
\text { belonging to the } \\
\text { institution }\end{array}$ & Low & Low medium & High \\
\hline Mentor/apprentice ratio & $\begin{array}{l}1 \text { teacher for } \\
15-20 \text { students }\end{array}$ & $\begin{array}{l}1 \text { teacher for } 15-20 \\
\text { students }\end{array}$ & $\begin{array}{l}\text { Approx. } 1 \text { licensed } \\
\text { person for } 1 \text { apprentice }\end{array}$ \\
\hline Main aim & Student learning & Student understanding & Production \\
\hline $\begin{array}{l}\text { Teacher/supervisor's } \\
\text { main objective }\end{array}$ & Teaching & Explaining & Operating \\
\hline Collaborative work & $\begin{array}{l}\text { Rarely prescribed, } \\
\text { sometimes even } \\
\text { punished }\end{array}$ & Often introduced & Common \\
\hline Situations and problems & Artificial & Created & Real \\
\hline Mistakes & Accepted & Tracked down & Forbidden \\
\hline $\begin{array}{l}\text { Asking questions, requesting } \\
\text { help when needed }\end{array}$ & Welcome & Welcome & Expected \\
\hline $\begin{array}{l}\text { Asking questions, requesting } \\
\text { unnecessary help }\end{array}$ & Tolerated & Accepted & Not welcome \\
\hline
\end{tabular}

General aim of the research project

The overall aim of our research project is to track stability and changes in motivation, beliefs and attitudes over the duration of an apprenticeship and to analyse their sensitivity to contextual dimensions. There are three lines of enquiry: in the first step, the various intracontextual developments will be analysed, contrasting stability and changes occurring within each context (the workplace and each of the course types at school). Second, possible cross-contextual developments will be identified, by examining whether the differences in motivation, beliefs or attitudes between contexts remain constant or change during training. Finally, the project will examine whether experiences gained in one of the contexts can influence an apprentice's later judgments towards another context that is whether transcontextual influences can be seen over time in the judgments made by apprentices regarding their motivation to learn, their beliefs or their attitudes.

The present paper reports the results of two different studies carried out within this project; the first one examining the development of apprentices' beliefs and motivation to learn, the second the changes in their attitudes towards seeking help and their readiness at different levels of their training to seek help when they need it at the workplace and at the school.

\section{Study 1}

From a social cognition perspective, motivation to learn is often defined as a person's expressed learning intentions in a given subject based on various readings of his or her 
present situation, such as subjective competence or self-efficacy beliefs for the task he or she is confronted with, as well as personal judgments of the utility of what is being learned and the attractiveness of the learning environment, be it the school, the programme or the social partners engaged in that environment (Seegers and Boekaerts 1993).

The importance of taking into account the parameters of the context in which learning is to be accomplished has now been established (Ames 1992; Urdan 1999; Volet and Järvelä 2001). Many authors have pointed out, though, that the same skill or subject is often learned in more than one context (Volet 1999; Davidson and Phelan 1999; Gurtner et al. 2001; Horn et al. 2008). Language acquisition and good manners are paradigmatic examples since the way you express yourself or behave is clearly dependant on the context of situation: who you are with and where you are. Learning to teach and learning to become a nurse also require multi-context learning. The goal of the present study is to investigate whether motivation to learn professional skills varies across the different contexts in which the profession is learned, and if so, how.

\section{Methodology/research design}

This is a longitudinal study with repeated measures collected over 3 years from a sample of 313 apprentices of various professional sectors, including commerce, arts and crafts or industry. Of these, 137 were females and 176 males. At the end of each year of their training, they were asked to complete a questionnaire regarding their motivation to learn (learning intentions) in each of the three contexts (company, general education courses and specific courses for the chosen profession), and also how they judged their competence (self-efficacy beliefs), the utility of what they were shown and the attractiveness of these three contexts. The questionnaire was adapted from Ntamakiliro et al. (2000). In order to distinguish the contexts clearly, all the questionnaires were divided into three sections; all the items of section 1 refer to motivation at the company where the apprentice was undergoing the practical part of his/her training. Section 2 focuses on their motivation for general education courses taken at the school, such as languages, mathematics or history; section 3 refers to the courses or workshops which are more specific to the professional sector in which the participants are involved, in areas such as electricity, mechanics, or office skills. The same items, arranged in a different order, are repeated over the three sections. For instance, items such as: I am ready to work hard (learning intention), I really feel competent (self-efficacy beliefs), I think that what we are doing is important (perceived utility of what is being learned) or I like the kind of things I am doing (attractiveness) are preceded in section 1 by in the company in which I am working, in section 2 by in the general education courses attended at the school and in section 3 by in the specific courses. All the questions are formulated as 7-point Likert scales from 1 for complete disagreement to 7 for complete agreement. At the end of year 3, we asked apprentices whether they would agree to be interviewed briefly on how they retrospectively evaluated their apprenticeship. Only 16 apprentices accepted. To reduce the formality of these interviews, they were deliberately not recorded.

As Fig. 1 shows, the repetition of identical measures taken at the end of each school year (years 1,2 and 3) for the three contexts makes it possible to detect the intra-contextual stability of a given indicator; by correlating the values taken at the same point in time for the same indicator in the three different contexts, cross-contextual tendencies can also be displayed. Finally, through hierarchical regression analysis, we are able to discover what we call transcontextual interactions, computing the additional percentage of the variance of a given indicator $\left(\Delta R^{2}\right)$ explained by the values observed for that same indicator within the remaining two contexts the year before. 
Fig. 1 Model of the three different types of effect studied in the present research

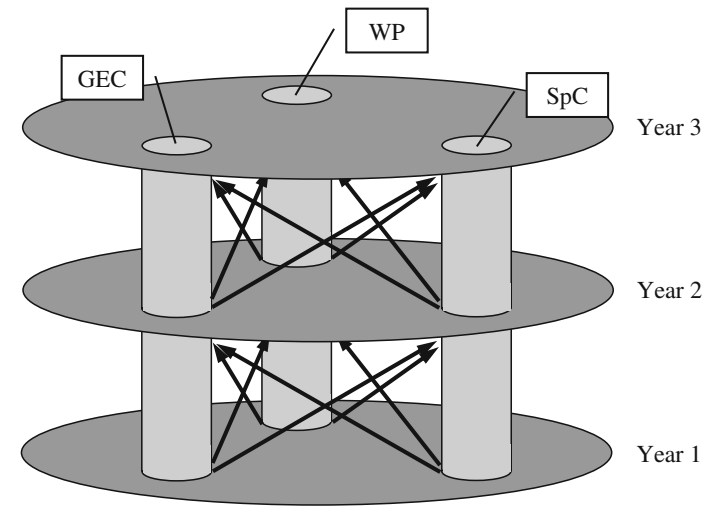

Legend: $\bigcirc$ Intra-contextual stability (GEC: General education courses ; WP: workplaceexperiences; $\mathrm{SpC}$ : Specific courses)

Cross-contextual influences (different contexts - same time)

Trans-contextual interactions (different contexts - different time)

\section{Results}

The data show that the level of motivation and its progression over time significantly differ from one context to another (see Fig. 2). $T$ tests performed on the means observed each year for all three contexts show that 28 of the 36 comparisons are significant at the .01 level (two-tailed). All the two by two comparisons are significant at the .05 level (two-tailed) with respect to learning intentions and self-efficacy beliefs. The only four non-significant mean comparisons at the .05 level concern the attractiveness of the two school contexts in year 1 of the training, the perception of the utility of these two contexts in

Development of learning intentions (motivation)

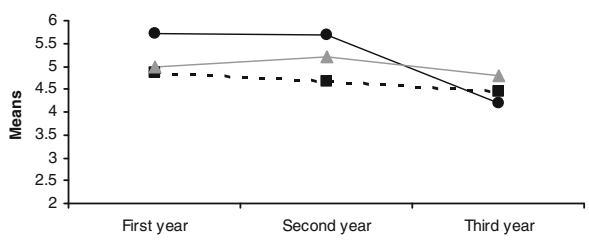

Development of perceived utility

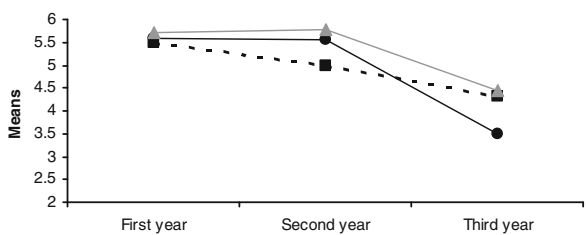

Development of attractiveness

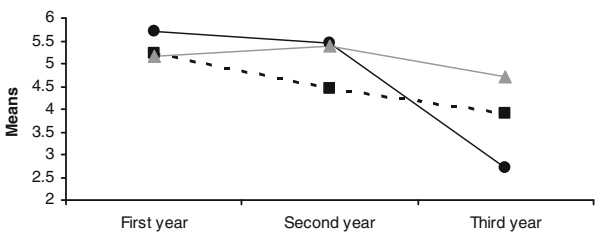

Development of self-efficacy beliefs

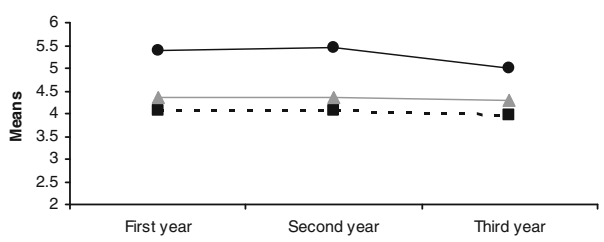

$\rightarrow$ Workplace $\quad$ - - - General education courses $\quad \longrightarrow$ Specific courses

Fig. 2 Development of motivation (learning intentions) and of three related beliefs in the three contexts of vocational education (workplace, general education courses and specific courses) over the years of training within the dual track system 
year 3 and two comparisons involving the workplace context-one with the general education courses in year 1 of the training with respect to apprentices' perceptions of the utility of what they are doing and the other with the specific courses in year 2 of their training with respect to the attractiveness of these two contexts. Globally, as they begin their training, apprentices are clearly more motivated to learn in the context of the company than at school; this is most evident for self-efficacy beliefs but also for attractiveness of the context and for learning intentions. However, the company context comes second in apprentices' perceptions of the usefulness of what they are doing in each context. The general education courses start as the least attractive, the context for which they have the weakest self-efficacy beliefs and learning intentions and the subjects, which they see as the least useful when they begin their training. During the second year of the training apprentices agree that the specific courses have become more attractive and produce a greater motivation to learn; while there is stability for the context of the workplace on three of the indicators, for the general education courses a decrease is apparent. In the third year of their training the decline, which had started earlier in the general education courses, now reaches the other two contexts, except with regard to self-efficacy beliefs. The drop is most dramatic in the context of the workplace, which is now seen as the least attractive of all three contexts, the least useful and the context triggering the lowest motivation to learn.

In order to gain a better understanding of such non-parallel developments in the different contexts, informal interviews were carried out with 16 apprentices and a closer look taken at the differing curricula. These post hoc inquiries brought useful information and confirmed that intra-contextual aspects can explain a large part of the results. At the workplace, apprentices frequently carry out similar and sometimes boring operations all through their training. Increasingly, they see them as rather repetitive and, as they grow more experienced, consider that they are not being given complex enough tasks. At the same time, as they approach their final exams, they understand that what they have been taught at school will be of great importance for exam success and thus for receiving their diploma. This explains why apprentices in the third year of their training suddenly consider both the general education and the specific courses to be more useful than what they are learning at the workplace.

If one considers the correlations across contexts however, evidence of cross-contextual effects can also be found. While between context correlations for the same indicator show a mean value of .30 when the two school contexts are compared, a higher mean value is obtained (.42) if one compares the workplace and the specific courses, that is one 'in school' and one 'out of school' context. No clear-cut school vs. workplace contrasts appear with respect to the four indicators of motivation tested in this study. This can be explained by the specific nature of the two different types of courses they have to attend at school. The general education courses remind them of when they were secondary school pupils, which was not a very successful time for them. Apprentices struggle to find any purpose in the further study of these general subjects now that they have left school to become professionals within a given labour sector. In contrast to this, the specific courses are new to them and the topics presented there are much easier to connect with the professional domain they have chosen and to which they now devote the rest of their time. The thematic proximity between what they see at the workplace and what they learn in the specific courses at school transcends the differences in location, causing apprentices to develop more analogous motivations and beliefs across these two different contexts than for the two school-based contexts.

In addition to intra-contextual and cross-contextual effects, can motivation and beliefs in one context be affected by experiences gained within one or more additional contexts? To 
test for possible diagonal effects (see Fig. 1), we performed hierarchical regression analyses on each of the four indicators, using $t_{1}$ values for the same context (block 1) and $t_{1}$ values for the other two contexts (block 2) to appreciate the Delta $R^{2}$ extra-contribution of the other contexts to the variability at $t_{2}$ of each specific context. We did the same for $t_{3}$ using $t_{2}$ values. Results of these analyses show that the additional effects of the remaining two contexts are generally low (between $0 \%$ and 5\%) and often non-significant. However, in seven of the 24 computed regressions the contribution of the previous measures within the other contexts was significant. Five of these cases concern the workplace. School courses at $t_{1}$ significantly contributed to perceived utility $\left(\Delta R^{2}=5 \%, p<.05\right)$, self-efficacy beliefs $\left(\Delta R^{2}=11 \%, p<.01\right)$ and learning intentions $\left(\Delta R^{2}=5 \%, p=.01\right)$ at the workplace at $t_{2}$ when controlling for the intra-contextual influence. In the same way, self-efficacy beliefs and learning intentions at the workplace at $t_{3}$ were significantly predicted (respectively $\Delta R^{2}=20 \%, p=.01$ and $\Delta R^{2}=18 \%$, $p=.01$ ) by the efficacy beliefs and the learning intentions displayed at school at $t_{2}$. Conversely, learning intentions regarding the general education courses were clearly predicted by learning intentions expressed at $t_{1}$ in the other two contexts $\left(\Delta R^{2}=5 \%, p<.05\right)$ and attractivity of the specific courses at $t_{2}$ was significantly predicted by the attractivity of the workplace and of the general education courses at $t_{1}\left(\Delta R^{2}=3 \%, p=.05\right)$. Although tiny, these effects prove that, in some cases, motivation and beliefs developed towards one context can be contaminated, positively or negatively, by the motivation and the beliefs experienced earlier in other contexts.

Further evidence for intra- and extra-contextual effects were gained from 'Study 2', which is described below.

\section{Study 2}

Along with a growing interest in the study of self-regulated learning, a number of researchers in motivation have analysed learners' attitudes and beliefs towards help and help seeking together with their help-seeking behaviours (Karabenick 2004; Nelson-Le Gall and Jones 1990; Newman 1994; Ryan and Pintrich 1997). Initially characterised as a dependant act revealing one's ignorance and incompetence, asking questions and requesting help is now seen as a proactive and mastery-oriented activity (Nelson-Le Gall 1987; Karabenick and Knapp 1991), which motivates students and allows them to attempt to overcome a temporary problem. In this respect, Newman (1994) distinguishes between adaptive help, a request for assistance that at the same time provides a better understanding of the problem (thus, decreasing the need for subsequent assistance on the same kind of problem) and maladaptative or expedient help, a request that simply hands over the problem in order to have it solved with minimal effort on the part of the person requesting help.

Despite this reconceptualization, it has been observed that students often avoid asking for help in order not to seem stupid or incompetent. Newman and Goldin (1990) observe that helpseeking avoidance is more prevalent among low achievers while Karabenick and Knapp (1991) note that it correlates with low self-esteem and low ability to use effective cognitive and learning strategies. Moreover, children with high intrinsic orientation prefer indirect help to direct help (Nelson-Le Gall and Jones 1990). Students considering themselves to be low in social competence see more potential threats from peers and therefore tend to avoid asking for help (Ryan and Pintrich 1997). Butler (1998) distinguishes at least three good reasons not to ask for help, the wish to remain autonomous, concerns about showing incompetence and general negative beliefs about the effectiveness of help. 
Other studies show that classroom characteristics and the attitudes of the potential helpers also orient students towards readiness or avoidance of seeking help. While a mastery-oriented classroom climate tends to motivate students to ask for help, performanceoriented classrooms discourage them from asking for help (Karabenick 2004; Ryan et al. 1998). Moreover, in mastery-oriented classes, teachers are seen as reacting more positively to help requests than in classes, which are high in performance orientation (Turner et al. 2002). If teachers are generally preferred as helpers to classmates (Newman and Schwager 1993), their attitudes and expected reactions can be determinant in students' decisions to ask for or to avoid asking for help. Strong personal relationships with their teachers boost students' readiness to seek help (Newman and Schwager 1993). More generally, environments with individualistic norms inhibit help seeking, while those with collectivist norms promote it (Sandoval and Lee 2006).

Up to now, the vast majority of studies have been carried out in academic settings (Karabenick and Newman 2006) but analogous reasons for not asking for help have been found at work also (Edmondson 2003).

\section{Methodology}

'Study 2' is a cross-sectional study involving 160 apprentices from year 1 through year 4 of their training. They completed a questionnaire dealing with their beliefs. They were asked whether help seeking is a useful strategy, both in order to overcome a difficulty and to make progress, about their own readiness to seek help when experiencing a problem, and about the type of help (adaptative or maladaptive) they prefer to ask for in each of the contexts, the workplace on the one hand, and the school on the other.

\section{Instrument}

A questionnaire was designed incorporating items from Karabenick (2004), Ryan et al. (1998) and Ryan and Pintrich (1997). Half of the questions explicitly relate to the school context; each of these items is duplicated and very slightly adapted to focus on the workplace context. For example, the item 'I think that asking questions at the workplace can help me completing my tasks' is paired with the item: 'I think that asking questions at school can help me to complete the exercises'. An item such as: 'At school, if I need help, I ask my fellow students to give me hints or clues rather than the final answer' has a parallel item phrased 'At the workplace, if I need help, I ask my co-workers to give me hints or clues rather than to do the task for me'. All the items are distributed randomly in the questionnaire and paired items never appear next to each other. Answers to all items are given on a 7 point scale ranging from $1=$ 'not at all true for me' to $7=$ 'totally true of me'. For dimensions composed of more than two items, mean scores are calculated separately, that is one for each context.

Participants One hundred and sixty apprentices from two different vocational schools in Switzerland answered the questionnaire. They were all preparing themselves for a technical profession, mainly within the wood sector (59), the machine industry (48), road construction (20), electricity/electronics (18) or car mechanics (15). They were between 15 and 20 years old. Forty-nine of them were in their first year of training, 30 in the second, 42 in the third and 39 in the fourth and final year of their training. Ninety-six per cent were 
male; $2 \times 4$ ANOVAs were computed to compare participants' attitudes towards help seeking between the two contexts after 1, 2, 3 and 4 years of training.

\section{Results}

Table 2 displays the means and the standard deviations for apprentices' attitudes and beliefs towards help seeking and their readiness to seek help, at school and at the workplace, for each year of the training.

A repeated measure analysis of variance of the findings displayed in Table 2, using the two contexts as the repeated measures, shows both a significant difference between the attitudes, beliefs and readiness to seek help in the two contexts $(F(1,156)=32.16, p=$ $0.000)$ and a significant context by year of training interaction $(F(3,156)=2.86, p=$ 0.039 ). If apprentices agree that they are more likely to ask for help at the workplace than at school, the difference between the two contexts is larger at the beginning of the training than towards its end. In fact, LSD multiple comparisons show that the mean difference between the two contexts is significantly smaller for year 4 than that observed in year 1 $(p=0.007)$ or $2(p=0.005)$.

These results again show clear intra-contextual influences on the attitudes and beliefs of the apprentices, but as they continue to evolve simultaneously in these two contexts, each week apprentices progressively tend to reduce that specific perception and more and more to construct context-independent attitudes and beliefs. The finding that this occurs as a reduction in readiness to ask for help at the workplace and by seeing help as becoming less useful in this context, rather than an increase in their propensity to ask for help at school, may be attributed to the fact that, with increasing experience, the number of situations in which they have to ask for help at the workplace decreases, making the necessity for requesting help less obvious. This tendency is less apparent at school because the difficulty level of the topics at school increases over the years of training much more than it does at the workplace.

\section{Discussion}

While the existence of contextual effects on a learner's motivation has long been accepted (see Volet and Järvelä 2001), it is increasingly clear that we need to consider learning as

Table 2 Means and standard deviations of apprentices' readiness to seek help at school and at the workplace respectively and the differences between the two contexts for each year of training

\begin{tabular}{|c|c|c|c|c|c|c|}
\hline \multirow[t]{2}{*}{ Context (year) } & \multirow[t]{2}{*}{$N$} & \multicolumn{2}{|c|}{ School } & \multicolumn{2}{|c|}{ Workplace } & \multirow[t]{2}{*}{ Workplace-school } \\
\hline & & Mean & Standard deviation & Mean & Standard deviation & \\
\hline 1 & 49 & 5.23 & 1.15 & 5.96 & .75 & 0.73 \\
\hline 2 & 30 & 5.30 & .86 & 6.08 & .67 & 0.78 \\
\hline 3 & 42 & 5.07 & 1.25 & 5.59 & 1.08 & 0.52 \\
\hline 4 & 39 & 5.04 & 1.14 & 5.13 & 1.16 & 0.09 \\
\hline Total & 160 & 5.16 & 1.14 & 5.68 & 1.00 & 0.52 \\
\hline
\end{tabular}


occurring within multiple contexts (Davidson and Phelan 1999; Gurtner and De Rocha Trindade 2008; Horn et al. 2008). Most of the time, these multiple contexts are activated simultaneously in the learner's mind, making it difficult for the researcher or educator to determine which context or combination of contexts is currently influencing the learner's motivation and reactions. The dual track vocational and educational system commonly used in Austria, Germany and Switzerland provides a situation in which it is possible to isolate the influences to a certain degree. With the contexts so clearly separated in time, space and social practices (see Table 1), different effects on an apprentice's motivation, beliefs or attitudes can be observed depending on which context he or she is prompted with. It proved unnecessary to immerse the participants physically in the differing contexts in order for the diversity to become apparent; the mere evocation of these contexts on paper was enough to elicit significant differences in the appraisals made by the apprentices and in their declared readiness to learn ('Study 1') or to ask questions and seek help when needed in these various contexts ('Study 2').

Contrary to what had been anticipated, however, no clear-cut differences between the school and the workplace contexts were observed which were valid for all the years of training. While in the first year of training, motivation and beliefs regarding the specific courses were closer to what was experienced within the other school context, that is, the general education courses, than to those for the workplace, towards the end of the second year, three of the four indicators used in 'Study 1' showed stronger correlations and closer appraisals between the specific courses and the workplace than between the two school-based types of courses. The proximity in topics and questions handled in the specific courses and at the workplace raised their attractiveness, perceived utility and learning intentions towards the specific courses, despite the very different physical settings in which these things were dealt with. Over the same period, for want of apparent connectedness with the kinds of activities apprentices were performing or watching at the workplace, motivation and beliefs towards the general education courses declined, broadening the gap between the different types of courses taken within the same institution. It is likely that, when asked to judge one's motivation towards one kind of activities, belonging to one specific context, individuals do not only take into consideration the context in which these activities are situated, but that their answers also relate to what they are experiencing in the other contexts. We propose to call this phenomenon, cross-contextual effects. Whether such effects mainly tend to sharpen the differences in someone's judgments or on the contrary, to bring them closer together, remains an open issue.

Our model also suggests that between-context influences may affect judgements regarding another context in a delayed way. As can be seen from the data, betweencontexts differences noted at the beginning of training often tended to disappear during the training, as the learner becomes more used to swapping contexts regularly each week. Such reductions in the differential effects of contexts can be seen as the consequence of a growing influence of experiences gained in another context (Schmid et al. 2005); we propose to call such effects transcontextual since they reveal delayed influences from one context on another. It is likely that these effects reveal the efforts made by the learner to reunify her/his perceptions, feelings and reactions in the presence of a singular global reality - in our data his or her future profession-which appears in different contexts; if such transcontextual effects can sustain the learner's motivation in less well appreciated domains, they may also affect it negatively, if the influence comes from a less well appreciated domain and contaminates a more positively construed domain or context. By learning to detect and exploit intra-, cross- and transcontextual effects on motivation, appraisals and attitudes, 
teachers and educators could become more effective in sustaining learners' motivation or at least in preventing it from falling too globally.

Acknowledgements This research was made possible through a grant from the Swiss National Science Foundation, FNRS no. 1113-061971.00 (Study 1) and a grant of the Swiss Federal Office for Professional Education and Technology, number BB.2006.0023 (Study 2).

\section{References}

Ames, C. (1992). Classrooms: goals, structures, and student motivation. Journal of Educational Psychology, $84,261-271$.

Bonoli, L., \& Ghisla, G. (2008). I sistemi formativi nei paesi di riferimento: Austria, Francia, Germania, Italia, Regno Unito e Svizzera. In G. Ghisla, L. Bonoli, \& M. Loi (Eds.), Economia della formazione professionale (pp. 3-64). Novara: UTET.

Butler, R. (1998). Determinants of help seeking: relations between perceived reasons for classroom helpavoidance and help-seeking behaviors in an experimental context. Journal of Educational Psychology, 90, 630-643.

Davidson, A. L., \& Phelan, P. (1999). Students' multiple worlds: an anthropological approach to understanding students' engagement with school. In T. C. Urdan (Ed.), The role of context. Advances in motivation and achievement (Vol. 11, pp. 233-273). Stamford: JAI Press.

Edmondson, A. C. (2003). Managing the risk of learning: psychological safety in work teams. In M. West (Ed.), International handbook of organizational teamwork. London: Blackwell.

Gurtner, J.-L., \& De Rocha Trindade, B. (2008). Contrasting attitudes towards help-seeking at vocational school and at the workplace. Paper presented at the 4th EARLI SIG 14 Learning and professional development conference, University of Jyväskylä, Finland, 27-29 August.

Gurtner, J.-L., Monnard, I., \& Genoud, P. A. (2001). Towards a multilayer model of context and its impact on motivation. In S. Volet, \& S. Järvelä (Eds.), Motivation in learning contexts: Theorical advances and methodological implications (pp. 189-208). Oxford: Pergamon.

Horn, I. S., Nolen, S. B., Ward, C., \& Campbell, S. S. (2008). Developing practices in multiple worlds: the role of identity in learning to teach. Teacher Education Quarterly, 35, 61-72.

Karabenick, S. A. (2004). Perceived achievement goal structure and college student help seeking. Journal of Educational Psychology, 96, 569-581.

Karabenick, S. A., \& Knapp, J. R. (1991). Relationship of academic help seeking to the use of learning strategies and other instrumental achievement in college students. Journal of Educational Psychology, $83,221-230$.

Karabenick, S. A., \& Newman, R. S. (Eds.). (2006). Help seeking in academic settings: goals, groups, and contexts. Mahwah: Erlbaum.

Nelson-Le Gall, S. (1987). Necessary and unnecessary help-seeking in children. Journal of Genetic Psychology, 148, 53-62.

Nelson-Le Gall, S., \& Jones, E. (1990). Cognitive-motivational influences on the task-related help-seeking behavior of black children. Child Development, 61, 581-589.

Newman, R. S. (1994). Adaptive help-seeking: a strategy of self-regulated learning. In D. Schunk \& B. Zimmerman (Eds.), Self-regulation of learning and performance: issues and educational applications (pp. 283-301). Hillsdale: Erlbaum.

Newman, R. S., \& Goldin, L. (1990). Children's reluctance to seek help with schoolwork. Journal of Educational Psychology, 82, 92-100.

Newman, R. S., \& Schwager, M. T. (1993). Student perceptions of the teacher and classmates in relation to reported help seeking in math class. The Elementary School Journal, 94, 3-17.

Ntamakiliro, L., Monnard, I., \& Gurtner, J.-L. (2000). Mesure de la motivation scolaire des adolescents: construction et validation de trois échelles complémentaires. Orientation scolaire et professionnelle, 29, 673-693.

Ryan, A. M., \& Pintrich, P. R. (1997). "Should I ask for help?" The role of motivation and attitudes in adolescents' help seeking in math class. Journal of Educational Psychology, 89, 329-341.

Ryan, A. M., Gheen, M. H., \& Midgley, C. (1998). Why do some students avoid asking for help? An examination of the interplay among students' academic efficacy, teachers' social-emotional role, and the classroom goal structure. Journal of Educational Psychology, 90, 528-535. 
Sandoval, B. A., \& Lee, F. (2006). When is seeking help appropriate? Now norms affect help-seeking in organizations. In S. A. Karabenick, \& R. S. Newman (Eds.), Help-seeking in academic settings: Groups, goals, and contexts (pp. 151-173). Mahwah, NJ: Erlbaum.

Schmid, S., Hofer, M. F., Reinders, H., \& Fries, S. (2005). Value orientations and action conflicts in students' everyday life: an interview study. European Journal of Psychology of Education, 20(3), 243-257.

Seegers, G., \& Boekaerts, M. (1993). Task motivation and mathematics achievement in actual task situations. Learning and Instruction, 3, 133-150.

Turner, J. C., Midgley, C., Meyer, D. K., Gheen, M., Anderman, E. M., Kang, Y., et al. (2002). The classroom environment and students' reports of avoidance strategies in mathematics: a multi-method study. Journal of Educational Psychology, 94, 88-106.

Urdan, T. (1999). "Foreword". In M. L. Maehr, \& P. R. Pintrich (Eds.), Advances in Motivation and Achievement: The Role of Context (Vol. 11, pp. IX-XI). Greenwich, CT: JAI Press.

Volet, S. (1999). Motivation within and across cultural-educational contexts: a multi-dimensional perspective. In T. C. Urdan (Ed.), The role of context. Advances in motivation and achievement (Vol. 11, pp. 185-231). Stamford: JAI Press.

Volet, S., \& Järvelä, S. (Eds.). (2001). Motivation in learning contexts. Theoretical advances and methodological implications. Amsterdam: Pergamon.

Jean-Luc Gurtner. Department of Education, University of Fribourg $(\mathrm{CH})$. University of Fribourg, rue Faucigny 2, 1700 Fribourg, Switzerland. E-mail: jean-luc.gurtner@unifr.ch

Current themes of research:

Motivation. Vocational education and training. Mobile learning technology. Multilingualism.

Relevant publications:

Gurtner, J.-L., Cattaneo, A., Motta, E., \& Mauroux, L. (2011). How Often and for What Purposes Apprentices Seek Help in Workplaces: A Mobile Technology-Assisted Study. Vocations and Learning, 4, 113-131.

Gurtner, J.-L., Hitz, A., \& Mauroux, L. (2008). Assessing learners readiness to ask for help in action using mobile technologies. International Conference on Motivation, University of Turku, August 21-23.

Gurtner, J.-L., Gulfi, A., Monard, I., \& Schumacher, J. (2006). Est-il possible de prédire l'évolution de la motivation pour le travail scolaire de l'enfance à l'adolescence? Revue Française de Pédagogie, 155, 21-34.

Gurtner, J.-L., Monnard, I., Genoud, P.A. (2001). Towards a multilayer model of context and its impact on motivation. In S. Volet \& S. Järvelä (Eds.). Motivation in Learning Contexts, (pp. 189-208). London: Pergamon.

Philippe A. Genoud. Department of Education and Department of Psychology, University of Fribourg $(\mathrm{CH})$. University of Fribourg, rue Faucigny 2, 1700 Fribourg, Switzerland. E-mail: philippe.genoud@unifr.ch

Current themes of research:

Interpersonal relations and affective processes in the classroom. Psychometrics.

\section{Relevant publications:}

Genoud, P.A., Ruiz, G., \& Gurtner, J.-L. (2009). Evolution de la motivation scolaire des adolescents: différences selon la filière et le genre. Revue Suisse des Sciences de l'Education, 31(2), 377-395.

Genoud, P.A., Brodard, F., \& Reicherts, M. (2009). Facteurs de stress et burnout chez les enseignants de l'école primaire. Revue Européenne de Psychologie Appliquée, 59(1), 37-45.

Genoud, P.A. (2008). Pour une meilleure compréhension de l'estime de soi : liens entre la perception de soi et les indicateurs sociométriques. Nouveaux Cahiers de la Recherche en Education, 11(1), 35-48.

Genoud, P.A., \& Reicherts, M. (2008). Le burnout chez les étudiants universitaires et ses liens avec 1'ouverture émotionnelle. Revue de Psychoéducation, 37(2), 227-244. 
Alida Gulfi. Department of Education, University of Fribourg, $(\mathrm{CH})$. University of Fribourg, rue Faucigny 2, 1700 Fribourg, Switzerland, and, University of Applied Sciences of Western Switzerland, rue JeanProuvé 10, 1762 Givisiez (Switzerland). E-mail: Alida.Gulfi@hef-ts.ch

Current themes of research:

Intercultural approaches. Professional practices. Professional integration. Suicidology.

Relevant publications:

Gulfi, A., Genoud, P.A, Schumacher, J., \& Gurtner, J.-L. (2005). Impact du climat social en entreprise sur l'évolution de la motivation des apprentis. Congrès annuel de la Société Suisse pour la recherche en éducation, Lugano, 21-23 septembre.

Bernardo de Rocha Trindade. Department of Education, University of Fribourg (CH). University of Fribourg, rue Faucigny 2, 1700 Fribourg, Switzerland. E-mail: Bernardo.derocha@unifr.ch

Current themes of research:

Social dynamics of group work. Collaborative planning and problem solving.

Relevant publications:

Gurtner, J.-L., \& De Rocha Trindade (2008). Contrasting attitudes towards help-seeking at vocational school and at the workplace. EARLI SIG 14 Conference, University of Jyväskulä, 28.08.2008.

Jérôme A. Schumacher. University of Teacher Education, Fribourg, 36 rue de Morat, 1700-Fribourg, Switzerland. E-mail: Schumacherje@edufr.ch

Current themes of research:

Motivation for musical education in primary school. Creativity in teacher education. Music teachers' practices.

Relevant publications:

Schumacher, J. A., Coen, P.-F., \& Steiner, M. (2010). Les futurs enseignants et la créativité: quelles conceptions? Formation et pratiques d'enseignement en questions. Revue des HEP de Suisse romande et du Tessin, 11, 115-131.

Schumacher, J. A. (2009). Présentation d'une grille d'analyse des pratiques du professeur d'instrument de musique. Recherche en éducation musicale, 27, 43-62. 